\title{
ARTICLE
}

\section{Dynamic formation of single-atom catalytic active sites on ceria-supported gold nanoparticles}

Yang-Gang Wang ${ }^{1,2}$, Donghai Mei ${ }^{1}$, Vassiliki-Alexandra Glezakou' ${ }^{1}$ Jun $\mathrm{Li}^{2,3}$ \& Roger Rousseau ${ }^{1}$

Catalysis by gold supported on reducible oxides has been extensively studied, yet issues such as the nature of the catalytic site and the role of the reducible support remain fiercely debated topics. Here we present $a b$ initio molecular dynamics simulations of an unprecedented dynamic single-atom catalytic mechanism for the oxidation of carbon monoxide by ceriasupported gold clusters. The reported dynamic single-atom catalytic mechanism results from the ability of the gold cation to strongly couple with the redox properties of the ceria in a synergistic manner, thereby lowering the energy of redox reactions. The gold cation can break away from the gold nanoparticle to catalyse carbon monoxide oxidation, adjacent to the metal/oxide interface and subsequently reintegrate back into the nanoparticle after the reaction is completed. Our study highlights the importance of the dynamic creation of active sites under reaction conditions and their essential role in catalysis.

\footnotetext{
${ }^{1}$ Institute for Interfacial Catalysis, Pacific Northwest National Laboratory, Richland, Washington 99352, USA. ${ }^{2}$ Department of Chemistry, Tsinghua University, Beijing 100084, China. ${ }^{3}$ Environmental Molecular Sciences Laboratory, Pacific Northwest National Laboratory, Richland, Washington 99352 , USA. Correspondence and requests for materials should be addressed to R.R. (email: roger.rousseau@pnnl.gov) or to J.L. (email: junli@tsinghua.edu.cn).
} 
E ver since Haruta, Hutchings and others ${ }^{1-3}$ found that nanosized gold particles, supported by metal oxides, were highly reactive for a variety of important catalytic reactions, gold has been widely used as a catalyst. Extensive studies have been devoted to understanding the chemical nature of high reactivity of oxide supported gold $(\mathrm{Au})$ particles $^{4-10}$. Though it is generally recognized that the Au-oxide interfacial perimeter plays an important role, the chemical nature of the active sites and the details of the reaction mechanism are still hotly debated. This is partly because of the complexity of the systems, whose reactivity is affected by many factors, such as the structural and electronic properties of $\mathrm{Au}$ particles, the electronic interaction between the support and Au particles, the reactants and products, and finite temperature effects ${ }^{4}$. Nearly all of the theoretical studies on the $\mathrm{Au} /$ oxide system were based on carefully selected model clusters of surfaces, where the tendency of Au nanoparticles and surface to exhibit reconstruction, large amplitude motions and disorder at finite temperatures were not fully accounted for. As a prominent example, ceria $\left(\mathrm{CeO}_{2}\right)$ has been found to be a particularly effective support for gold particles in catalysing reactions such as CO oxidation and water-gas shift reactions ${ }^{9,10}$. Generally, the high reactivity is attributed to the excellent redox properties of ceria, such as easy formation and diffusion of oxygen defects, high capacity of oxygen storage and release, and facile acceptance/release and transport of excess electrons in a polaronic state derived from a narrow $4 \mathrm{f}$-band ${ }^{9,10}$. Various studies $^{11-14}$ have identified the interface sites between ceria support and gold particles as vital in the catalytic reactions. Recent evidence ${ }^{15-17}$ has led to the claim that the active sites are, in actuality, positively charged single gold atoms bound to the support by O linkages. Furthermore, environmental transmission electron microscopy analyses ${ }^{18}$ also showed that gold nanoparticles on a $\mathrm{CeO}_{2}$ support change their shapes at the interfacial area in response to alternating oxidizing and reducing atmospheres. These observations highlight the necessity of understanding the nature of reactive sites on ceria-supported $\mathrm{Au}$ nanocatalysts, at actual reaction conditions, that is, at elevated temperature and in the presence of dynamic reacting species.

In our recent report ${ }^{19}$, we showed that a stable, high-symmetry, tetrahedral $\mathrm{Au}_{20}$ cluster on a rutile $\mathrm{TiO}_{2}$ support exhibited liquidlike motion on charge transfer and $\mathrm{CO}$ adsorption. The large adsorbate-induced structural reconstruction also allowed for facile transfer of adsorbed $\mathrm{CO}$ to the metal/oxide interface, where the $\mathrm{CO}_{2}$ formation reaction occurs. Connected with this phenomenon was the finding that charge transfer between the
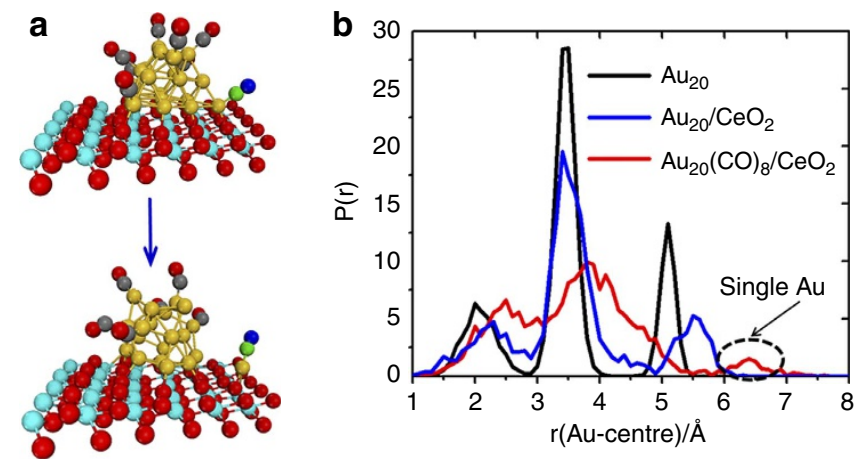

Figure 1 | MD simulations. (a) Initial and final configuration of the AIMD simulation for a $\mathrm{CeO}_{2}(111)$ supported $\mathrm{Au}_{20}$ cluster with eight $\mathrm{CO}$ adsorption. (b) The probability distribution functions $P\left(r_{c m}\right)$ of the $A u$ atoms relative to the centre-of-mass of the $\mathrm{Au}_{20}$ based on $\sim 20 \mathrm{ps} \mathrm{MD}$ simulations at $700 \mathrm{~K}$. (Yellow sphere: Au; cyan sphere: $\mathrm{Ce}$; red sphere or blue sphere: $\mathrm{O}$; green sphere or grey sphere: $\mathrm{C}$ ) nanoparticle and support enabled low-energy redox reactions during the catalytic cycle. These ideas motivated us to consider how generalizable these findings are to other reducible oxides and whether other related phenomena could be involved.

In this work, we present results from density functional theory (DFT)-based $a b$ initio molecular dynamics (AIMD) simulations to explore the reactivity and dynamics of ceria-supported $\mathrm{Au}$ catalysts for the $\mathrm{CO}$ oxidation reaction. Our simulations take into account both the dynamics of atoms in the Au metal particle, ceria support, reactants and products, as well as the excess charge carriers within the partially reduced ceria surface. We find that, in the presence of $\mathrm{CO}$, a cationic $\mathrm{Au}^{+}{ }_{-} \mathrm{CO}$ species is created. This species migrates directly onto the ceria support and, via a strong coupling with the redox properties of the ceria, it enables lowenergy barriers for redox steps in the catalytic cycle. After the catalytic cycle is complete, the Au single atom is reintegrated into the Au nanoparticle, indicating that the actual catalytic species only exists as a transient under operating conditions.

\section{Results}

The behaviour of Au particles on a ceria support. As is known, the geometric and electronic properties of $\mathrm{Au}$ particles on the oxide support strongly affect the catalytic activity of Au nanocatalyst $^{4,20-23}$. Thus, we first performed AIMD simulations for ceria-supported $\mathrm{Au}_{20}$ cluster to illustrate how the finite temperature and the nature of the adsorbed species influence the morphology of gold nanoparticle, before examining the catalytic mechanism and the effect of particle size. Considering the extensive existence of oxygen vacancies on $\mathrm{CeO}_{2}$, we have removed one surface oxygen atom to model a partially reduced $\mathrm{CeO}_{2}$ support, on which we deposited the $\mathrm{Au}_{20}$ cluster, and allowed it to bind to the surface during a 20-ps AIMD trajectory at $T=700 \mathrm{~K}$. In a second step, we added an additional eight CO molecules on the cluster and allowed the system to further equilibrate for another 20 ps. This approach guaranteed a wellthermalized and unbiased structural model of $\mathrm{CO}$ adsorbed on a $\mathrm{CeO}_{2}$-supported $\mathrm{Au}_{20}$ cluster.

The distribution of the distance of $\mathrm{Au}$ atoms relative to the centre-of-mass of the $\mathrm{Au}_{20}$ cluster, $\mathrm{P}\left(\mathrm{r}_{\mathrm{cm}}\right)$ shown in Fig. 1a, can be used to characterize the structural fluctuation within each system. For the isolated $\mathrm{Au}_{20}$ cluster in the gas phase, its tetrahedral configuration is retained at the simulation temperature of $700 \mathrm{~K}$, and the $\mathrm{P}\left(\mathrm{r}_{\mathrm{cm}}\right)$ exhibits three well-defined peaks clearly separated by zero probability density between them, corresponding to three types of $\mathrm{Au}$ atoms. However, when $\mathrm{Au}_{20}$ is supported on a $\mathrm{CeO}_{2}(111)$ surface, Fig. $1 \mathrm{~b}$, it exhibits a distinct structural reconstruction and loses its tetrahedral configuration, which is manifested in $\mathrm{P}\left(\mathrm{r}_{\mathrm{cm}}\right)$ as broader peaks, compared with the isolated $\mathrm{Au}_{20}$ cluster. The particle-surface interaction are strong due to a gold-to-oxide charge transfer, resulting in partially oxidized $\mathrm{Au}$ atoms at the interface as evidenced by the appearance of unpaired electrons localized in the upper layer of $\mathrm{Ce}$ atoms when the nanoparticle is adsorbed.

The gold nanoparticle, however, shows appreciably enhanced structural flexibility when $\mathrm{CO}$ is co-adsorbed. It is found that $\mathrm{Au}_{20}$ exhibits a strong adsorption-induced surface reconstruction and extrudes many low-coordinated sites to bind CO. As a result, the function $\mathrm{P}\left(\mathrm{r}_{\mathrm{cm}}\right)$ for the $\mathrm{Au}$ nanoparticle exhibits significantly broader peaks with non-zero density between them. We further observed that $\mathrm{CO}$ diffusion proceeds in the same way as reported previously for $\mathrm{Au} / \mathrm{TiO}_{2}$ (ref. 19); $\mathrm{CO}$ does not move freely from one $\mathrm{Au}$ site to another, but rather diffuses as an adsorbed $\mathrm{Au}-\mathrm{CO}$ species (see Fig. 2 and Supplementary Fig. 1). Since CO oxidation is generally reported to happen at the gold-oxide interface, this finding is vital for understanding how the adsorbed CO species is 


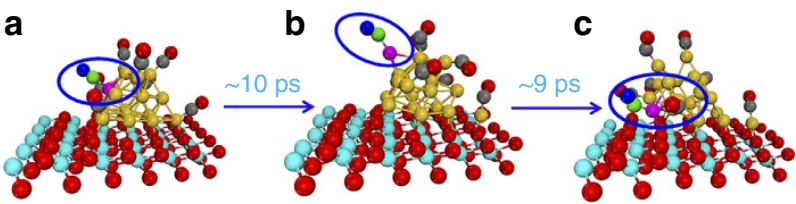

Figure 2 | Diffusion of Au-CO unit. (a-c) Selected snapshots of the MD trajectory for $\mathrm{Au}_{20} / \mathrm{CeO}_{2}$ with a circled $\mathrm{Au}-\mathrm{CO}$ unit to show the diffusion process. (yellow or pink sphere: $\mathrm{Au}$; cyan sphere: $\mathrm{Ce}$; red sphere or blue sphere: O; green sphere or grey sphere: C)

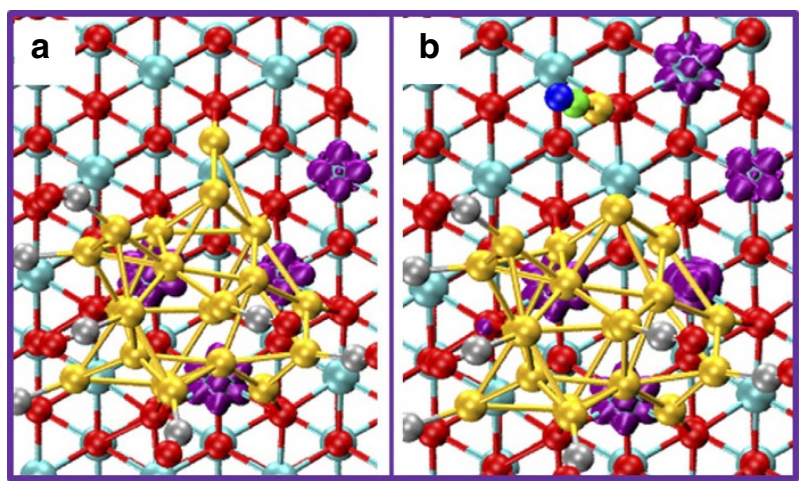

Figure 3 | Three-dimensional isosurface of the spin densities. (a) Spin densities (purple areas)for the $\mathrm{Au} / \mathrm{CeO}_{2}$ without an isolated $\mathrm{Au}-\mathrm{CO}$ unit at the interfacial area. (b) Spin densities with an isolated Au-CO unit at the interfacial area. Note, the configuration in $\mathbf{a}$ is geometry-optimized configuration by removing one $\mathrm{CO}$ from the configuration in $\mathbf{b}$.

transported to the perimeter site (Fig. 2a-c). These results indicate that the $\mathrm{Au}$ nanoparticle is rather flexible in geometry and can change its morphology on $\mathrm{CO}$ adsorption, consistent with previous theoretical studies ${ }^{19,24-26}$. However, the ceriasupported system exhibits one unique feature. As shown in Fig. 1, an $\mathrm{Au}-\mathrm{CO}$ species migrates away from the gold nanoparticle directly onto the ceria support adjacent to the metal/oxide interfacial area. In the function $\mathrm{P}\left(\mathrm{r}_{\mathrm{cm}}\right)$ for $\mathrm{Au}_{20}$, the isolated $\mathrm{Au}$ atom could also be identified by a peak at around $6.4 \AA$ that is well separated from the rest of the probability function.

To understand the nature of this specific single-Au atom species, we consider its electronic properties with and without $\mathrm{CO}$ adsorption. When $\mathrm{CO}$ is removed from the isolated $\mathrm{Au}-\mathrm{CO}$, the $\mathrm{Au}$ atom is readily reintegrated into the $\mathrm{Au}$ nanoparticle (see Fig. 3a), even in the course of a simple local geometry optimization. By monitoring the spin density, we observed four excess electrons in the $\mathrm{CeO}_{2}$ lattice, two more than the number that an oxygen defect can create, indicating that the $\mathrm{Au}$ nanoparticle transfers additional charges to the surface ${ }^{27}$. Once the $\mathrm{CO}$ is adsorbed at the $\mathrm{Au}$ atom, and the $\mathrm{Au}-\mathrm{CO}$ moiety becomes isolated from the rest of the $\mathrm{Au}$ nanoparticle, an additional excess electron becomes localized on an adjacent $\mathrm{Ce}$ site in the topmost layer of the support. Concurrently, the charge of this $\mathrm{Au}$ atom increases from $+0.10|\mathrm{e}|$ to $+0.42|\mathrm{e}|$ This indicates that by moving to the oxygen site, the single Au atom transfers one electron to the support, resulting in a species that can be formally described as an adsorbed $\mathrm{Au}^{+}+\mathrm{CO}$. Our results are consistent with previous findings ${ }^{28,29}$ that the single $\mathrm{Au}$ atom on $\mathrm{CeO}_{2}$ surface can transfer its $6 \mathrm{~s}$ electron to the unoccupied $4 \mathrm{f}$ orbital of Ce. We note that the observed excess electrons are mobile on the AIMD timescale, showing hops between Ce sites in the topmost surface layer on the order of 2 ps, in accord with our previous work on partially reduced ceria ${ }^{30}$. owing to the nature of ligand-to-metal electron donation of the $\mathrm{Au}-\mathrm{CO}$ bond, $\mathrm{CO}$ is expected to energetically favour binding at the positively charge $\mathrm{Au}$ site. To understand the formation of single $\mathrm{Au}$ atom, we further considered the formation energies of the single $\mathrm{Au}$ atom with or without $\mathrm{CO}$ adsorption:

$$
\begin{gathered}
E_{1}=E\left(\mathrm{Au}_{n-1}+\mathrm{Au}\right)-E\left(\mathrm{Au}_{n}\right) \\
E_{2}=E\left(\mathrm{Au}_{n-1}+\mathrm{Au}-\mathrm{CO}\right)-E\left(\mathrm{Au}_{n}-\mathrm{CO}\right)
\end{gathered}
$$

where $E_{1}$ is the energy change by taking one $\mathrm{Au}$ atom from the $\mathrm{Au}_{n}$ nanoparticle to the next-nearest oxygen site on ceria surface and $E_{2}$ is the energy associated with taking one $\mathrm{Au}-\mathrm{CO}$ unit from the $\mathrm{Au}_{n}$ nanoparticle to the next-nearest oxygen site. Since in our AIMD simulations $\mathrm{CO}$ adsorption can only cause a lowcoordinated $\mathrm{Au}$ atom to be isolated from the $\mathrm{Au}$ nanoparticle at the interface, we only consider a single four-coordinated $\mathrm{Au}$ site at the interface. For the $\mathrm{Au}_{20}$ cluster on ceria surface, the calculated $E_{1}$ is $1.21 \mathrm{eV}$, indicating that for the bare $\mathrm{Au}$ nanoparticle it is energetically unfavourable for the $\mathrm{Au}$ atom to break away from the Au nanoparticle. While the calculated $E_{2}$ is $-0.81 \mathrm{eV}$, it indicates that forming an isolated $\mathrm{Au}^{+}{ }_{-} \mathrm{CO}$ could be thermodynamically favourable. Our work is consistent with the recent findings ${ }^{31}$ that $\mathrm{CO}$ adsorption on a $\mathrm{CeO}_{2}$-supported $\mathrm{Au}_{4}$ cluster leads to the formation of $\mathrm{Au}-\mathrm{CO}$ species. Considering the $\mathrm{CO}$ oxidation on $\mathrm{CeO}_{2}$-supported $\mathrm{Au}$ nanoparticles is reported to proceed at room temperature ${ }^{4,32}$, we further considered the possible reaction paths for $\mathrm{Au}-\mathrm{CO}$ dissociation into the adjacent oxygen site on $\mathrm{Au}_{20} / \mathrm{CeO}_{2}$ using climbing image nudged-elastic-band method (see Supplementary Fig. 2). The barrier is estimated to be $\sim 0.20-0.62 \mathrm{eV}$, which indicates that the isolated $\mathrm{Au}-\mathrm{CO}$ can easily be form at room temperature. Combined with the fact that $\mathrm{Au}-\mathrm{CO}$ species on the $\mathrm{Au}$ cluster are mobile (Fig. 2), we also conclude that even if $\mathrm{CO}$ does not initially adsorb directly at the interface site, the isolated $\mathrm{Au}^{+}{ }_{-} \mathrm{CO}$ will eventually form.

Inasmuch as in our previous simulation ${ }^{19}$ we did not observe any isolated $\mathrm{Au}-\mathrm{CO}$ on $\mathrm{TiO}_{2}$ support, we checked the singleatom formation energies on $\mathrm{Au}_{20} / \mathrm{TiO}_{2}$ system. The isolated $\mathrm{Au}$ atom without adsorbed $\mathrm{CO}$ is not stable at the oxygen site and slips to the adjacent five-coordinated $\mathrm{Ti}$ site spontaneously during the geometry optimization, in accord with Metiu's recent report ${ }^{33,34}$. However, its formation energies are positive ( $E_{2}=1.25 \mathrm{eV}$ at the oxygen site; $E_{1}=0.96 \mathrm{eV}$ and $E_{2}=0.90 \mathrm{eV}$ at the $\mathrm{Ti}$ site), implying that stabilizing the oxidized $\mathrm{Au}^{+}{ }_{-} \mathrm{CO}$ on a $\mathrm{TiO}_{2}$ support is unfavourable. This is traced back to the fact that rutile $\mathrm{TiO}_{2}$ is less capable of accepting an electron from an $\mathrm{Au}-\mathrm{CO}$ to stabilize a cationic species and highlights the point that the $\mathrm{CeO}_{2}$ support, as a stronger oxidizer, can.

Generally, the reactivity for an oxidation reaction is strongly affected by the electronic chemical potential (work function, $W$ ) of the catalyst. We found that creation of the isolated $\mathrm{Au}^{+}{ }_{-} \mathrm{CO}$ increased $W$ from 4.8 to $5.1 \mathrm{eV}$, which indicates that the Ceria is more likely to take electrons by becoming a stronger oxidizing agent, and it is itself more easily reduced. This implies that the single $\mathrm{Au}$ atom at the interfacial area creates an activation centre for oxidation processes and, thus, is expected to be more reactive, in accord with recent reports on highly reactive single-atom catalysts on metal oxide ${ }^{35,36}$. In the next section, we further consider the possible reaction mechanism for $\mathrm{CO}$ oxidation at the isolated $\mathrm{Au}$ species on $\mathrm{CeO}_{2}$ surface and directly compare with the process at the cluster/oxide interface

Reaction mechanism for CO oxidation. Recent theoretical studies have proposed ${ }^{9,14,37}$ three $\mathrm{CO}$ oxidation mechanisms on $\mathrm{CeO}_{2}$-supported Au particles: (1) $\mathrm{CO}$ oxidation by co-adsorbed $\mathrm{O}_{2}$ on $\mathrm{Au}$ particles, (2) $\mathrm{CO}$ oxidation by adsorbed $\mathrm{O}_{2}$ at the 
interfacial site and (3) $\mathrm{CO}$ oxidation by a lattice oxygen ion from $\mathrm{CeO}_{2}$ substrate. In the present study, we examined a large number of adsorption configurations of $\mathrm{O}_{2}$ on $\mathrm{Au}_{20}$ cluster or interfacial sites, but we found that the $\mathrm{O}_{2}$ hardly binds at these sites $\left(E_{\mathrm{ads}}<-0.2 \mathrm{eV}\right)$. These results suggest that $\mathrm{CO}$ oxidation with preadsorbed $\mathrm{O}_{2}$ at the Au nanoparticle or the interface sites are less likely to be operative for larger Au particles, and lower reduction levels of the support, as is expected to be the case for a reaction that is run under oxidizing conditions. Therefore, we consider the reaction of $\mathrm{CO}$ with the lattice oxygen ion, in accord with extensive experimental studies ${ }^{18,38-40}$ that strongly indicate that $\mathrm{CO}$ oxidation proceeds via a Mars-van Krevelen mechanism (that is, a redox) mechanism.

We first considered the oxidation of $\mathrm{CO}$ that preadsorbs on the gold nanoparticle, comparable with previous theoretical studies ${ }^{14}$. The detailed pathways and energetics are shown in Supplementary Fig. 3. We found that CO easily reacts with the lattice oxygen ion, and forms a bent $\mathrm{CO}_{2}^{-}$intermediate. This is a highly exothermic process $(\Delta E=-0.94 \mathrm{eV})$ with a low-energy barrier $\left(\Delta E^{\dagger}=0.25 \mathrm{eV}\right)$. However, the subsequent $\mathrm{CO}_{2}$ desorption is quite unfavourable, with a desorption energy of $1.29 \mathrm{eV}$. As the lattice oxygen ion is being extracted, there is a concurrent reduction of the surface that leaves two excess electrons localized on the Ce $4 \mathrm{f}$ states. After the formation of an oxygen defect, $\mathrm{O}_{2}$ adsorption from the gas phase at this site is highly favourable in energy and the subsequent oxidization of the second $\mathrm{CO}$ to $\mathrm{CO}_{2}$ proceeds with a low-energy barrier $\left(\Delta E^{\dagger}=0.45 \mathrm{eV}\right)$. Overall, the rate determining step for the oxidation of $\mathrm{CO}$ preadsorbing on the gold particle involves desorption of the first $\mathrm{CO}_{2}$ with a high-enough energy barrier such that the reaction would not be anticipated to proceed at room temperature. However, the result is in direct contradiction with the experimental findings $s^{32,41}$ that show the reaction of $\mathrm{CO}$ oxidation with lattice oxygen ion in the interfacial area at the room temperature. In short, for the current $\mathrm{Au}_{20}$ system on a mildly reduced ceria support, none of the three previously proposed routes corroborate this experimental observation.

As the adsorption of $\mathrm{CO}$ at the perimeter sites could lead to the formation of an $\mathrm{Au}^{+}-\mathrm{CO}$ near the interfacial area, we further consider the reaction mechanism for $\mathrm{CO}$ oxidation at this specific isolated site. The reaction pathway and associated energetics are shown in Fig. 4. For convenience of discussion, we also track the Bader charges of the isolated $\mathrm{Au}$ and the number of $\mathrm{Ce}^{3+}$ throughout the catalytic process for each stationary point on the potential energy surface, shown in Table 1 . In the proposed mechanism, we start the reaction process from the $\mathrm{Au}$ nanoparticle without an isolated $\mathrm{Au}$ site (Configuration i in Fig. 4). First, the adsorption of $\mathrm{CO}$ at the low-coordinate site leads to the formation of an isolated $\mathrm{Au}^{+}-\mathrm{CO}$ unit (Configuration ii). By overcoming a barrier of $0.77 \mathrm{eV}$, the $\mathrm{CO}$ can react with the adjacent oxygen ion, forming a bent $\mathrm{CO}_{2}^{-}$intermediate (Configuration iii). Further, this bent intermediate only requires $0.27 \mathrm{eV}$ of energy to release the $\mathrm{CO}_{2}$ molecule into the gas phase (Configuration iv). In this process, the single $\mathrm{Au}$ atom migrates towards and occupies the oxygen defect after $\mathrm{CO}_{2}$ desorption. The Bader charge of the Au atom significantly decreases from +0.40 to -0.56 , while the number of $\mathrm{Ce}^{3+}$ ions remains unchanged. These results indicate that in tandem with the removal of the lattice oxygen ion, the two resulting excess electrons are transferred to the single $\mathrm{Au}$ atom, leading to a conversion of the oxidation state from $\mathrm{Au}^{+}$to $\mathrm{a} \mathrm{Au}^{-}$that fills the oxygen vacancy. In other words, this single atom stabilizes the reduction of the ceria surface leading to more facile $\mathrm{CO}_{2}$ desorption. This observation is consistent with our previous analysis of work function, which suggests in the presence of a charged $\mathrm{Au}^{+}+\mathrm{CO}$, Ceria is locally a stronger oxidizing agent.
However, the resulting $\mathrm{Au}^{-}$species, which fills the oxygen vacancy, is in direct contrast with the $\mathrm{CO}$ oxidation on the $\mathrm{Au}$ nanoparticle where the two resulting excess electrons become localized at two $\mathrm{Ce}^{3+}$ ions.

To complete the catalytic cycle, we consider the second half of the $\mathrm{CO}$ oxidation reaction. Once the single $\mathrm{Au}$ atom has moved into the oxygen defect, it is harder to bind $\mathrm{CO}\left(E_{\mathrm{ads}}=-0.16 \mathrm{eV}\right)$ or $\mathrm{O}_{2}\left(E_{\mathrm{ads}}=-0.10 \mathrm{eV}\right)$ molecules. At first glance, this would indicate that the catalyst is deactivated for further $\mathrm{CO}$ oxidation, which is consistent with a recent study ${ }^{17}$ showing that $\mathrm{Au}$ at the oxygen defect has no further reactivity for $\mathrm{CO}$ oxidation. However, further $\mathrm{CO}$ oxidation can be achieved by extracting the $\mathrm{Au}$ atom out of the vacancy back to the Au cluster, so that it could bind the second $\mathrm{CO}$ while the vacancy becomes available for $\mathrm{O}_{2}$ adsorption. We noted that our AIMD simulations for $\mathrm{Au}_{20} / \mathrm{CeO}_{2}$ with one oxygen vacancy did not show any $\mathrm{Au}$ atom permanently occupying the oxygen vacancy, which implies that it may also be possible that the single Au atom may be able to reintegrate with the Au cluster (Configuration vi). With this in mind, we further performed CI-NEB calculations, as well as, constrained AIMD computation of a potential of mean force for the single $\mathrm{Au}$ reintegrating into the $\mathrm{Au}$ cluster without the presence of $\mathrm{CO}$. We found that the single Au atom, at the oxygen vacancy, can move up and reintegrate within into Au cluster with a barrier of $0.89 \mathrm{eV}$ on the potential energy surface and $0.81 \mathrm{eV}$ on the free energy surface. This process is slightly exothermic with Au preferring energetically to be reintegrating into the Au cluster by $-0.10 \mathrm{eV}$. Note these relatively low barriers are consistent with room temperature activity. Once the $\mathrm{Au}$ is back to the $\mathrm{Au}$ cluster, the second $\mathrm{CO}$ can form another stable $\mathrm{Au}^{+}{ }_{-} \mathrm{CO}$ species near the interfacial area (Configuration vii), by exothermic adsorption energy of $-1.12 \mathrm{eV}$. During these processes, the Bader charge of the single Au atom increases from -0.54 to 0.40 $e^{-}$. The surface accumulates two more $\mathrm{Ce}^{3+}$ ions, indicating that by moving out of the oxygen defect, the Au ion returns two excess electrons to the lattice. This result implies that the driving force for the Au moving out of the oxygen defect comes from the attraction of the $\mathrm{Au}$ cluster, and it also explains the recent experimental findings ${ }^{42,43}$ that the clustering of $\mathrm{Au}$ from an isolated $\mathrm{Au}$ precursor results in an increase of the $\mathrm{CO}$ oxidation activity. Recent theoretical studies ${ }^{17,31}$ also showed that the small $\mathrm{Au}_{n}$ cluster $\left(\mathrm{Au}_{2}\right.$ or $\left.\mathrm{Au}_{3}\right)$ are catalytically reactive for $\mathrm{CO}$ oxidation without filling one $\mathrm{Au}$ into the oxygen defect site. Since the oxygen vacancy is recreated, the $\mathrm{O}_{2}$ molecule in the gas phase could easily fill into the oxygen defect with a high binding energy of $-1.51 \mathrm{eV}$, eliminating the two excess electrons and forming a peroxo $\mathrm{O}_{2}^{2-}$ species (Configuration viii). As a result, the $\mathrm{CO}$ at the single Au site only needs to overcome a small barrier of $0.65 \mathrm{eV}$ to react with the peroxo $\mathrm{O}_{2}^{2-}$ species, releasing the second $\mathrm{CO}_{2}$ (Configuration ix). During this process, the $\mathrm{Au}$ atom gradually loses its adsorbed $\mathrm{CO}$ and returns to the $\mathrm{Au}$ nanoparticle, completing the catalytic cycle. Overall, the proposed mechanism suggests that the rate-limiting step for $\mathrm{CO}$ oxidation is the removal of the single $\mathrm{Au}$ out of the oxygen vacancy. The barrier of the rate-limiting step at the single atom site is $0.89 \mathrm{eV}$, which is far lower than that at the gold particles $(1.29 \mathrm{eV})$, suggesting that the transient monatomic species are the active sites in $\mathrm{CeO}_{2}$-supported $\mathrm{Au}$ catalyst.

For a direct comparison with the experimental observation for the room temperature $\mathrm{CO}$ oxidation $^{32,41}$, we made a simple estimation of the reaction rate in the form of an attempt frequency multiplied by a Boltzmann factor, that is, $v=v_{0} \exp \left(-E_{a} / k_{\mathrm{B}} T\right)$ and assuming $v_{0}=10^{13} \mathrm{~s}^{-1}$, a reasonable value for most oxides as suggested by Marrochelli and Yildiz ${ }^{44}$. From this formula, the range of temperatures at which the reaction process could occur, within a minimum range of rate 
a

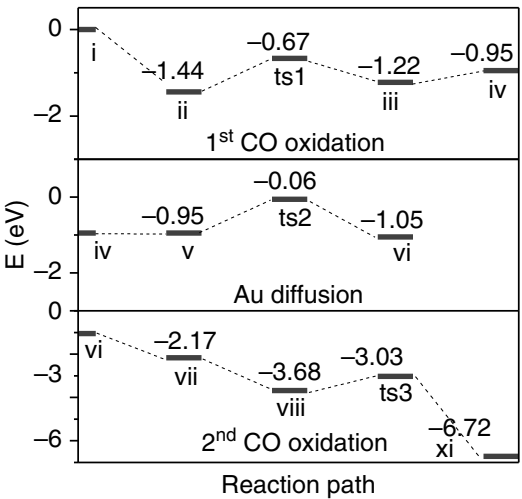

b

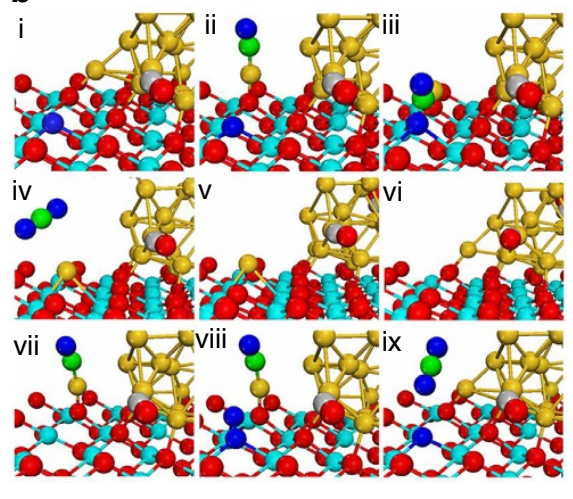

C

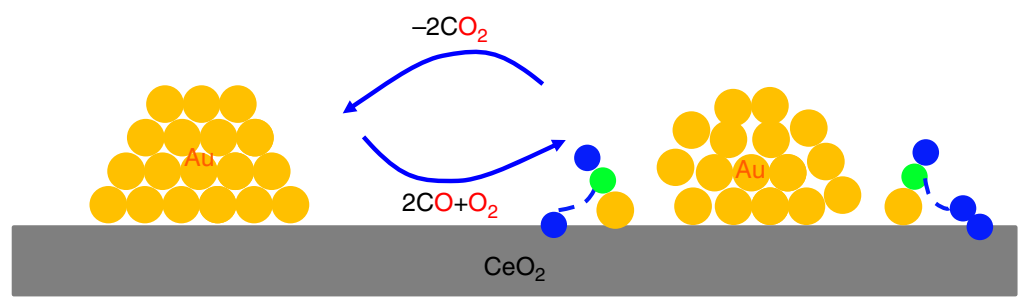

Figure 4 | Proposed reaction mechanism for CO oxidation at single Au site. (a) Reaction pathways, (b) configurations of reactants, intermediates and products, and (c) schematic representation of the dynamic behavior at the interface. The catalytic processes proceed as the following steps: (1) i-ii, CO adsorption leads to the formation of isolated $\mathrm{Au}-\mathrm{CO}$; (2) ii-ts1-iii, $\mathrm{CO}$ preadsorbing at the single Au site reacts with the lattice oxygen ion, forming a bent intermediate; (3) iii-iv-v, $\mathrm{CO}_{2}$ desorbs into the gas phase and at the same time the Au atom fills into the oxygen defect; (4) v-ts2-vi, the Au atom at the oxygen defect moves back to the Au cluster; (5) vi-vii, the second $\mathrm{CO}$ adsorption leads to the formation of isolated $\mathrm{Au}-\mathrm{CO}$; (6) vii-viii, the $\mathrm{O}_{2}$ adsorption at the oxygen defect. (7) viii-ts3-xi, the second $\mathrm{CO}$ reacts with the adsorbed $\mathrm{O}_{2}$ species, forming a $\mathrm{CO}_{2}$ molecule. At the same time, the Au returns the Au nanoparticle, completing the catalytic cycle. (The configurations for transition states are shown in Supplementary Fig. 4. Yellow sphere: Au; cyan sphere: Ce; red sphere or blue sphere: O; green sphere: $\mathrm{C}$.

Table 1 | The Bader charges of the single $\mathrm{Au}$ atom and the number of $\mathrm{Ce}^{3+}$ ions in the system.

\begin{tabular}{|c|c|c|c|c|c|c|c|c|c|}
\hline $\mathrm{q}(\mathrm{Au}) / \mathrm{e}-$ & 0.10 & 0.42 & 0.04 & -0.56 & -0.54 & 0.11 & 0.40 & 0.46 & 0.10 \\
\hline
\end{tabular}

constant $0.01 \sim 1 \mathrm{~s}^{-1}$, are estimated to be $300-340 \mathrm{~K}$, consistent with room temperature activity. We also performed constrained MD simulations to obtain the free energy barrier at $300 \mathrm{~K}$ for the migration of the Au atom towards the Au cluster (Supplementary Fig. 5). This simulation allows for the sampling of collective motions, such as the restructuring of the entire Au particle on reintegration of the $\mathrm{Au}$ ad-atom, and thus would be expected to better account for both the energy and entropic components of the process. The free energy barrier is estimated to be $0.81 \mathrm{eV}$ and based on the transition state theory formalism $v=k_{\mathrm{B}} T / h$ $\exp \left(-\Delta G^{\dagger} / k_{\mathrm{B}} T\right)$ the rate constant at $300 \mathrm{~K}$ is estimated to be $0.1 \mathrm{~s}^{-1}$, indicating that the process could occur several times per minute at room temperature.

Above, we proposed that the $\mathrm{Au}$ cluster could drive the $\mathrm{Au}$ atom out of the vacancy. We also noted that an isolated Au atom at the oxygen defect could also be directly pulled out of the oxygen defect by an adsorbed $\mathrm{CO}$, with a barrier of $0.85 \mathrm{eV}$, and a highly exothermic reaction energy of $-1.06 \mathrm{eV}$. Since the initially $\mathrm{CO}$ adsorption is very weak (only $-0.16 \mathrm{eV}$ ), this process will resemble an Eley-Rideal mechanism (the energy barrier is 0.85$0.16=0.69 \mathrm{eV}$ ) with a relatively low rate at reaction conditions where $\mathrm{CO}$ oxidation is typically performed. However, it may still happen under CO-rich conditions, where the high partial pressure of $\mathrm{CO}$ would significantly increase the sticking possibility of $\mathrm{CO}$ at the single $\mathrm{Au}$ site, and would enhance the reaction probability for the second $\mathrm{CO}$ oxidation step without changing the subsequent steps in reaction mechanism. In addition, recent theoretical studies by Song et $a l^{45,46}$ also proposed a relevant mechanism for $\mathrm{CO}$ oxidation and propylene oxidation at an isolated $\mathrm{Au}$ site, which are compatible with our findings.

Since the single $\mathrm{Au}$ atom is induced by $\mathrm{CO}$ adsorption at the interfacial area, it is its mobility that ultimately determines where the CO oxidation proceeds. In Supplementary Fig. 6, we show the reaction paths and energetics for Au diffusion to another oxygen site away from the Au nanoparticle. With the adsorption of $\mathrm{CO}$, the single $\mathrm{Au}$ atom has to overcome a high barrier of $1.14 \mathrm{eV}$ to diffuse from the interface to the next oxygen site, indicating that the diffusion of $\mathrm{Au}-\mathrm{CO}$ unit on the ceria surface is improbable at ambient conditions. As the barrier for $\mathrm{CO}$ reacting with the lattice oxygen is smaller $(0.77 \mathrm{eV})$ than the diffusion barrier, the $\mathrm{Au}^{+}$ $\mathrm{CO}$ is expected to oxidize appreciably faster than it can diffuse. We further consider a single $\mathrm{Au}$ atom away from the $\mathrm{Au}$ nanoparticle without CO adsorption. Similarly, the barrier for the diffusion away from the interface is much higher $(1.59 \mathrm{eV})$. Especially, when considering the inverse diffusion, the Au atom at the oxygen site only needs to overcome a very low barrier of $0.37 \mathrm{eV}$ to diffuse back towards the Au nanoparticle. The process 


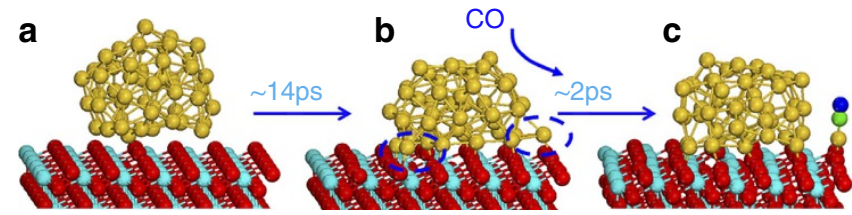

Figure 5 | Snapshots of $\mathbf{M D}$ simulation for $\mathrm{CeO}_{2}$-supported $\mathbf{A u}_{50}$ cluster. (a) Initial configuration of $\mathrm{Au}_{50} / \mathrm{CeO}_{2}$. (b) the snapshot of $\mathrm{Au}_{50} / \mathrm{CeO}_{2}$ at $\sim 14 \mathrm{ps}$. (c) the snapshot for the MD simulation with one $\mathrm{CO}$ initially adsorbed at the low-coordinated site. The low coordinate sites in (b) are circled in dotted line. See Supplementary Information for more snapshots to demonstrate the formation of low-coordinated sites frequently during the MD simulation.

is highly exothermic with a reaction energy of $-1.22 \mathrm{eV}$ and is the result of the above-mentioned propensity for the $\mathrm{Au}$ atoms to reintegrate with the nanoparticle when CO is not present. Taken together, these results demonstrate that single Au atom catalysis for $\mathrm{CO}$ oxidation would occur predominantly at the interfacial area.

Nanoparticle size effects. Since our AIMD simulations for $\mathrm{Au}_{20} / \mathrm{CeO}_{2}$ only show the formation of the isolated $\mathrm{Au}^{+}{ }_{-} \mathrm{CO}$ species at the low-coordinated sites, one may ask if the formation of the isolated $\mathrm{Au}^{+}{ }_{-} \mathrm{CO}$ species is determined by the specific model cluster and how applicable are these findings to large $\mathrm{Au}$ particles. Therefore, we further performed AIMD simulations for a bigger $\mathrm{Au}_{50}$ cluster $(\sim 1.5 \mathrm{~nm})$ on $\mathrm{CeO}_{2}$ support, which initially had no low-coordinate site at the interface area, shown in Fig. 5. We observed that the low-coordinate sites formed at the interface area, revealing that for even $1 \mathrm{~nm}$ Au particles, or larger, the lowcoordination sites should always exist at the interface. We further considered the formation energy of the isolated $\mathrm{Au}-\mathrm{CO}$ species on the $\mathrm{CeO}_{2}$ surface. In Table 2, we list the single-Au formation energies for $\mathrm{Au}_{10}, \mathrm{Au}_{20}$ and $\mathrm{Au}_{50}$. Without $\mathrm{CO}$ adsorption, the formation energies are endothermic for all three $\mathrm{Au}$ clusters, indicating that the creation of an isolated $\mathrm{Au}$ ad-atom is energetically unfavourable in all cases. Conversely, in the presence of $\mathrm{CO}$, the adsorption energies at isolated $\mathrm{Au}^{+}$sites for all clusters become exothermic, illustrating how formation of this species near the metal/oxide interface becomes thermodynamically favourable. We find that the above-mentioned formation energies are all within the same energy range with a variance of $0.3 \mathrm{eV}$ and no discernible trend indicating that this general result is not particularly influenced by the cluster size. We further performed a short ( $\sim 5 \mathrm{ps})$ AIMD simulation for $\mathrm{CeO}_{2}$-supported $\mathrm{Au}_{10}$ and $\mathrm{Au}_{50}$, where $\mathrm{CO}$ molecules are initial located at a lowcoordination interfacial $\mathrm{Au}$ site, to compare with our $\mathrm{Au}_{20}$ results. In agreement with our analysis above, we observe spontaneous formation of an $\mathrm{Au}^{+}+\mathrm{CO}$ atom at the interface for both cases within only a few ps, see Fig. $5 c$ and Supplementary Fig. 7.

In summary, we find that, for both smaller and larger $\mathrm{Au}$ nanoparticles, the surface-adsorbed $\mathrm{Au}^{+}{ }^{-}-\mathrm{CO}$ can be formed readily by $\mathrm{CO}$ adsorption. We speculate that under realistic conditions, small-size Au particles, with potentially a higher ratio of low coordinate sites at the interface than the large particles, should produce more single $\mathrm{Au}$ atom on $\mathrm{CO}$ adsorption. This conclusion is also consistent with our AIMD simulations on $\mathrm{Au}_{10} / \mathrm{CeO}_{2}$ with four adsorbed $\mathrm{CO}$ molecules, where we observed two single-Au atoms at the interface (Supplementary Fig. 7).

\section{Discussion}

In the present study, we performed static DFT calculations and $a b$ initio molecular dynamic simulations to gain insight on the reaction mechanism of $\mathrm{CO}$ oxidation at the interfacial area.
Table 2 | The formation energy of single Au atom at interfacial area.

\begin{tabular}{lccc} 
& $\mathbf{A u}_{\mathbf{1 0}}$ & $\mathbf{A u}_{\mathbf{2 0}}$ & $\mathbf{A u}_{\mathbf{5 0}}$ \\
\hline$E_{1}(\mathrm{eV})$ & 1.55 & 1.21 & 1.50 \\
$E_{2}(\mathrm{eV})$ & -0.50 & -0.81 & -0.73 \\
\hline
\end{tabular}

A new, dynamic, single-atom catalytic mechanism is established for $\mathrm{CO}$ oxidation on $\mathrm{Au} / \mathrm{CeO}_{2}$ catalysts, arising from a transient $\mathrm{Au}^{+}{ }_{-} \mathrm{CO}$ species. During the reaction process, a single $\mathrm{Au}^{+}$ atom acts as charge acceptor for enhanced $\mathrm{CO}$ adsorption and transport. This species considerably lowers the barriers for $\mathrm{CeO}_{2}$ reduction, effectively promoting the $\mathrm{CO}$ oxidation reaction. However, the active species, an $\mathrm{Au}^{+}{ }_{-} \mathrm{CO}$ ion, emerges only in the presence of $\mathrm{CO}$, and otherwise reintegrates with the $\mathrm{Au}$ nanoparticle. It is this monoatomic species that is able to couple its redox processes effectively with those of the support to enhance the redox processes, whilst the Au nanoparticle shows little evidence of coupling of its charge state with that of the oxide during the catalytic cycle.

Our study touches on a very important concept in the heterogeneous catalysis, namely that the actual catalytic active centre may be created only under reaction conditions and may not necessarily be easy to identify ex situ. The current study adds a layering to this concept by suggesting that, in the present case, the formation of the active site is a dynamic process occurring at the support oxide/metal particle interface. Our results promote the concept that the dynamic behaviour induced by the reactants at the interfacial area may be an overlooked aspect on the catalysis on reducible supports.

\section{Methods}

DFT parameters. All DFT calculations were performed using the CP2K package ${ }^{47}$. The exchange-correlation energy was described by the generalized-gradient approximation with spin-polarized Perdew-Burke-Ernzerh functional ${ }^{48}$. The wavefunctions were expanded in an optimized double- $\zeta$ Gaussian basis sets ${ }^{30,49}$ with an auxiliary plane wave basis set with a cutoff energy of 500 Rydberg ${ }^{50}$. Core electrons have been modelled by scalar relativistic norm-conserving pseudo potentials ${ }^{51}$ with $12,6,1$ and 4 valence electrons for $\mathrm{Ce}, \mathrm{O}, \mathrm{H}$ and $\mathrm{C}$, respectively. Brillouin zone integration is performed with a reciprocal space mesh consisting of only the gamma point. The DFT $+\mathrm{U}$ method, based on the Mullikan 4f state population analysis, was used to describe the Ce $4 \mathrm{f}$ electrons. A $U$ value of $7.0 \mathrm{eV}$ was used to reproduce the correct band gap of $3.2 \mathrm{eV}$, gap state location of $1.3 \mathrm{eV}$ above the valence band, and work function of $4.6 \mathrm{eV}$ for $\mathrm{CeO}_{2}$, which ensure that the redox chemistry is reproduced correctly. The detail tests and discussion can be found in our recent study ${ }^{30}$ and in the Supplementary methods. We observed many localized $4 \mathrm{f}$ electrons on $\mathrm{CeO}_{2}$-supported $\mathrm{Au}$ clsuter, which are mobile and can be localized at many different $\mathrm{Ce}$ sites in the simulations. This may lead to $0.1-0.3 \mathrm{eV}$ difference for the energetics, as is discussed in our previous study ${ }^{30}$. The location and energy of the transition state was performed using the climbing image nudged-elastic-band method (CI-NEB) ${ }^{52,53}$ including 9 replicas. The convergence criterion for the maximum force is set as $2 \times 10^{-3}$ atomic units. Vibrational analysis was further used to confirm the transition states corresponded to true saddle points on the potential energy surface with only one imaginary frequency.

Computational models. The $\mathrm{CeO}_{2}(111)-\mathrm{p}(5 \times 6)$ surface with one oxygen defect was used to model the $\mathrm{CeO}_{2}$ substrate, consisting of $4 \mathrm{O}$-Ce-O tri-layers (12 atomic layers), and only the bottom $\mathrm{Ce}$ atomic-layer were frozen while the remaining layers were allowed to relax. The slab was repeated periodically with a vacuum layer of $20 \AA$ in the direction of the surface normal. A tetrahedral $\mathrm{Au}_{20}$ cluster, which has been well characterized in previous studies, was chosen to model Au particles. The benchmark test of current approach with respect to a family of $\mathrm{Au}_{20}$ isomers can be found in our recent study ${ }^{19}$. To consider the nanoparticle size effect, $\mathrm{Au}_{10}$ (planar) and $\mathrm{Au}_{50}$ cluster were chose to model the different size of gold nanoparticles (the coordinates are listed in Supplementary Data 1).

AIMD simulations. All $a b$ initio MD simulations were performed by sampling the canonical ensemble employing Nose-Hoover thermostats ${ }^{54,55}$ with a time step of $0.5 \mathrm{fs}$ at a finite temperature of 300 or $700 \mathrm{~K}$. On the basis of simple geometry optimization, $\mathrm{CeO}_{2}$-supported $\mathrm{Au}_{20}$ cluster is estimated to be able to bind up to 10 
$\mathrm{CO}$ molecules and the average binding energy is $0.87 \mathrm{eV}$ per $\mathrm{CO}$. This result is consistent with our recent study ${ }^{19}$ on $\mathrm{TiO}_{2}$-supported $\mathrm{Au}_{20}$ cluster where we also found the system can at most bind $10 \mathrm{CO}$. Therefore, in our MD simulations, we considered both low coverage and high coverage of $\mathrm{CO}$ on the Au cluster to explore the behaviour of $\mathrm{CO}$-induced reconstruction. Since the relatively short timescales of AIMD limit sampling to only very fast, low-energy barrier events and preclude the observation of slow processes, the high temperature simulations could more rapidly explore a large volume of phase space. On the basis of a simple estimation according to $10^{13}{ }_{*} \exp \left(-E_{a} / R T\right)$, the rate constant for a reaction with an energy barrier of $0.5 \mathrm{eV}$ at $700 \mathrm{~K}$ is around $0.0025 \mathrm{ps}^{-1}$, this means that the process can happen only one time every $400 \mathrm{ps}$. Therefore, only the reaction process with the energy barrier lower than $0.5 \mathrm{eV}$ may be observed in our MD simulations at $700 \mathrm{~K}$ due to the limitation of the timescale (10-30 ps).

\section{References}

1. Haruta, M., Kobayashi, T., Sano, H. \& Yamada, N. Novel gold catalysts for the oxidation of carbon monoxide at a temperature far below $0{ }^{\circ} \mathrm{C}$. Chem. Lett. 2, 405-408 (1987).

2. Haruta, M. Size-and support-dependency in the catalysis of gold. Catal. Today 36, 153-166 (1997).

3. Hutchings, G. J. Gold catalysis in chemical processing. Catal. Today 72, 11-17 (2002).

4. Hvolbæk, B. et al. Catalytic activity of Au nanoparticles. Nano Today 2, 14-18 (2007).

5. Vilhelmsen, L. B. \& Hammer, B. Identification of the catalytic site at the interface perimeter of au clusters on rutile $\mathrm{TiO}_{2}(110)$. ACS Catal. 4, 1626-1631 (2014).

6. Green, I. X., Tang, W., Neurock, M. \& Yates, Jr J. T. Insights into catalytic oxidation at the $\mathrm{Au} / \mathrm{TiO}_{2}$ dual perimeter sites. Acc. Chem. Res. 47, 805-815 (2013).

7. Wang, J. \& Hammer, B. Oxidation state of oxide supported nanometric gold. Top. Catal. 44, 49-56 (2007).

8. Farnesi Camellone, M. \& Marx, D. Nature and role of activated molecular oxygen species at the gold/titania interface in the selective oxidation of alcohols. J. Phys. Chem. C 118, 20989-21000 (2014).

9. Zhang, C., Michaelides, A. \& Jenkins, S. J. Theory of gold on ceria. Phys. Chem. Chem. Phys. 13, 22-33 (2010).

10. Paier, J., Penschke, C. \& Sauer, J. Oxygen defects and surface chemistry of ceria: quantum chemical studies compared to experiment. Chem. Rev. 113, 3949-3985 (2013).

11. Rodriguez, J. A. Gold-based catalysts for the water-gas shift reaction: active sites and reaction mechanism. Catal. Today 160, 3-10 (2011).

12. Zhou, Z., Kooi, S., Flytzani-Stephanopoulos, M. \& Saltsburg, H. The role of the interface in $\mathrm{CO}$ Oxidation on $\mathrm{Au} / \mathrm{CeO}_{2}$ multilayer nanotowers. Adv. Funct. Mater. 18, 2801-2807 (2008).

13. Longo, A. et al. Structure of the metal-support interface and oxidation state of gold nanoparticles supported on ceria. J. Phys. Chem. C 116, 2960-2966 (2011).

14. Kim, H. Y., Lee, H. M. \& Henkelman, G. CO oxidation mechanism on $\mathrm{CeO}_{2}$-Supported Au nanoparticles. J. Am. Chem. Soc. 134, 1560-1570 (2012).

15. Guan, Y. \& Hensen, E. Cyanide leaching of $\mathrm{Au} / \mathrm{CeO}_{2}$ : highly active gold clusters for 1, 3-butadiene hydrogenation. Phys. Chem. Chem. Phys. 11, 9578-9582 (2009).

16. Flytzani-Stephanopoulos, M. Gold atoms stabilized on various supports catalyze the water-gas shift reaction. Acc. Chem. Res. 47, 783-792 (2013).

17. Camellone, M. F. \& Fabris, S. Reaction mechanisms for the $\mathrm{CO}$ oxidation on $\mathrm{Au} / \mathrm{CeO}_{2}$ catalysts: Activity of substitutional $\mathrm{Au}^{3+} / \mathrm{Au}^{+}$cations and deactivation of supported $\mathrm{Au}+$ adatoms. J. Am. Chem. Soc. 131, 10473-10483 (2009).

18. Ta, N. et al. Stabilized gold nanoparticles on ceria nanorods by strong interfacial anchoring. J. Am. Chem. Soc. 134, 20585-20588 (2012).

19. Wang, Y.-G., Yoon, Y., Glezakou, V.-A., Li, J. \& Rousseau, R. The role of reducible oxide-metal cluster charge transfer in catalytic processes: new insights on the catalytic mechanism of $\mathrm{CO}$ oxidation on $\mathrm{Au} / \mathrm{TiO}_{2}$ from ab initio molecular dynamics. J. Am. Chem. Soc. 135, 10673-10683 (2013).

20. Lopez, N. \& Nørskov, J. K. Catalytic CO oxidation by a gold nanoparticle: a density functional study. J. Am. Chem. Soc. 124, 11262-11263 (2002).

21. Yoon, B. et al. Charging effects on bonding and catalyzed oxidation of $\mathrm{CO}$ on $\mathrm{Au}_{8}$ clusters on MgO. Science 307, 403-407 (2005).

22. Remediakis, I. N., Lopez, N. \& Nørskov, J. K. CO oxidation on rutile-supported Au nanoparticles. Angew. Chem. In. Ed. 117, 1858-1860 (2005).

23. Gates, B. C. Supported gold catalysts: new properties offered by nanometer and sub-nanometer structures. Chem. Commun. 49, 7876-7877 (2013).

24. Pal, R. et al. Chemisorption-Induced 2D-3D-2D structural transitions in gold heptamer:(CO) $\mathrm{Au}_{\overline{7}}^{-}(\mathrm{n}=1-4)$. J. Phys. Chem. Lett. 2, 2288-2293 (2011).

25. Li, W.-K., Chu, L.-N., Gong, X.-Q. \& Lu, G. A comparative DFT study of adsorption and catalytic performance of Au nanoparticles at anatase and brookite $\mathrm{TiO}_{2}$ surfaces. Surf. Sci. 605, 1369-1380 (2011).
26. Zhai, H. J. et al. Chemisorption-induced structural changes and transition from chemisorption to physisorption in $\mathrm{Au}_{6}(\mathrm{CO})_{\mathrm{n}}^{-}(\mathrm{n}=4-9)$. J. Phys. Chem. $C$ 112, 11920-11928 (2008).

27. Zhang, C., Michaelides, A., King, D. A. \& Jenkins, S. J. Positive charge states and possible polymorphism of gold nanoclusters on reduced ceria. J. Am. Chem. Soc. 132, 2175-2182 (2010).

28. Liu, Z. P., Jenkins, S. J. \& King, D. A. Origin and activity of oxidized gold in water-gas-shift catalysis. Phys. Rev. Lett. 94, 196102 (2005).

29. Zhang, C., Michaelides, A., King, D. A. \& Jenkins, S. J. Structure of gold atoms on stoichiometric and defective ceria surfaces. J. Chem. Phys. 129, 194708 (2008).

30. Wang, Y.-G., Mei, D., Li, J. \& Rousseau, R. DFT + U study on the localized electronic states and their potential role during $\mathrm{H}_{2} \mathrm{O}$ dissociation and $\mathrm{CO}$ oxidation processes on $\mathrm{CeO}_{2}(111)$ surface. J. Phys. Chem. Lett. 4, 2256-2363 (2013).

31. Ghosh, P., Camellone, M. \& Fabris, S. Fluxionaality of Au clusters at ceria surfaces during $\mathrm{CO}$ oxidation: relationships among reactivity, size, cohesion, and surface defects from DFT simulations. J. Phys. Chem. C 117, 23082-23089 (2013).

32. Zhang, S. et al. $\mathrm{CO}$ oxidation activity at room temperature over $\mathrm{Au} / \mathrm{CeO}_{2}$ catalysts: disclosure of induction period and humidity effect. ACS Catal. 4, 3481-3489 (2014).

33. Chrétien, S. \& Metiu, H. Density functional study of the interaction between small Au clusters, Aun $(n=1-7)$ and the rutile $\mathrm{TiO}_{2}$ surface. II. Adsorption on a partially reduced surface. J. Chem. Phys. 127, 244708 (2007).

34. Chrétien, S. \& Metiu, H. Density functional study of the charge on Aun clusters $(\mathrm{n}=1-7)$ supported on a partially reduced rutile $\mathrm{TiO} 2$ (110): are all clusters negatively charged? J. Chem. Phys. 126, 104701 (2007).

35. Qiao, B. et al. Single-atom catalysis of CO oxidation using Pt1/FeOx. Nat. Chem. 3, 634-641 (2011).

36. Yang, X.-F. et al. Single-Atom catalysts: a new frontier in heterogeneous catalysis. Acc. Chem. Res. 46, 1740-1748 (2013).

37. Song, W. \& Hensen, E. J. M. A computational DFT study of CO oxidation on a $\mathrm{Au}$ nanorod supported on $\mathrm{CeO}_{2}(110)$ : on the role of the support termination. Catal. Sci. Technol. 3, 3020-3029 (2013).

38. Shapovalov, V. \& Metiu, H. Catalysis by doped oxides: CO oxidation by $\mathrm{Au}_{\mathrm{x}} \mathrm{Ce}_{1-\mathrm{x}} \mathrm{O}_{2}$. J. Catal. 245, 205-214 (2007).

39. Widmann, D., Leppelt, R. \& Behm, R. Activation of a Au/ $/ \mathrm{CeO}_{2}$ catalyst for the $\mathrm{CO}$ oxidation reaction by surface oxygen removal/oxygen vacancy formation. J. Catal. 251, 437-442 (2007).

40. Qian, K. et al. Influences of $\mathrm{CeO}_{2}$ microstructures on the structure and activity of $\mathrm{Au} / \mathrm{CeO}_{2} / \mathrm{SiO}_{2}$ catalysts in $\mathrm{CO}$ oxidation. J. Mol. Catal. A-Chem. 306, 40-47 (2009).

41. Deng, W., Carpenter, C., Yi, N. \& Flytzani-Stephanopoulos, M. Comparison of the activity of $\mathrm{Au} / \mathrm{CeO}_{2}$ and $\mathrm{Au} / \mathrm{Fe}_{2} \mathrm{O}_{3}$ catalysts for the $\mathrm{CO}$ oxidation and the water-gas shift reactions. Top. Catal. 44, 199-208 (2007).

42. Aguilar-Guerreroa, V. \& Gates, B. C. Genesis of a highly active cerium oxidesupported gold catalyst for CO oxidation. Chem. Commun. 30, 3210-3212 (2007).

43. Aguilar-Guerrero, V., Lobo-Lapidus, R. J. \& Gates, B. C. Genesis of a cerium oxide supported gold catalyst for $\mathrm{CO}$ oxidation: transformation of mononuclear gold complexes into clusters as characterized by $\mathrm{X}$-ray absorption spectroscopy. J. Phys. Chem. C 113, 3259-3269 (2009).

44. Marrocchelli, D. \& Yildiz, B. First-principles assessment of $\mathrm{H}_{2} \mathrm{~S}$ and $\mathrm{H}_{2} \mathrm{O}$ reaction mechanisms and the subsequent hydrogen absorption on the $\mathrm{CeO} 2(111)$ surface. J. Phys. Chem. C 116, 2411-2424 (2012).

45. Song, W. \& Hensen, E. J. M. Structure sensitivity in CO oxidation by a single Au atom supported on ceria. J. Phys. Chem. C 117, 7721-7726 (2013).

46. Song, W. et al. Selective propylene oxidation to acrolein by gold dispersed on $\mathrm{MgCuCr}_{2} \mathrm{O}_{4}$ spinel. ACS. Catal. 5, 1100-1111, 2015).

47. VandeVondele, J. et al. Quickstep: fast and accurate density functional calculations using a mixed Gaussian and plane waves approach. Comp. Phys. Commun. 167, 103-128 (2005).

48. Perdew, J. P., Burke, K. \& Ernzerhof, M. Generalized gradient approximation made simple. Phys. Rev. Lett. 77, 3865-3868 (1996).

49. VandeVondele, J. \& Hutter, J. Gaussian basis sets for accurate calculations on molecular systems in gas and condensed phases. J. Chem. Phys. 127, 114105 (2007).

50. Lippert, B. G., Hutter, J. \& Parrinello, M. A hybrid Gaussian and plane wave density functional scheme. Mol. Phys. 92, 477-488 (1997).

51. Goedecker, S., Teter, M. \& Hutter, J. Separable dual-space Gaussian pseudopotentials. Phys. Rev. B 54, 1703-1710 (1996).

52. Mills, G., Jónsson, H. \& Schenter, G. K. Reversible work transition state theory: application to dissociative adsorption of hydrogen. Surf. Sci. 324, 305-337 (1995).

53. Henkelman, G., Uberuaga, B. P. \& Jónsson, H. A climbing image nudged elastic band method for finding saddle points and minimum energy paths. J. Chem. Phys. 113, 9901 (2000). 
54. Nosé, S. A unified formulation of the constant temperature molecular dynamics methods. J. Chem. Phys. 81, 511 (1984).

55. Hoover, W. G. Canonical dynamics: equilibrium phase-space distributions. Phys. Rev. A 31, 1695-1697 (1985).

\section{Acknowledgements}

This work was supported by the US Department of Energy, Office of Science, Office of Basic Energy Sciences, Division of Chemical Sciences, Geosciences \& Biosciences and performed at Pacific Northwest National Laboratory (PNNL). PNNL is a multi-programme national laboratory operated by Battelle for the US Department of Energy. J.L. and Y.-G.W. were also financially supported by NKBRSF (2011CB932400) and NSFC (91026003, 21101098) of China. Computational resources were provided at W.R. Wiley Environmental Molecular Sciences Laboratory (EMSL), a national scientific user facility located at PNNL and sponsored by the US Department of Energy, Office of Science, Office of Biological and Environmental Research and at the National Energy Research Scientific Computing Center (NERSC) located at Lawrence Berkeley National Laboratory.

\section{Author contributions}

Y.-G.W. performed the calculations. D.M. and V.-A.G. contributed to the MD simulations. R.R., J.L. and V.-A.G. conceived the work and supervised the project.
Y.-G.W., V.-A.G., R.R. and J.L. co-wrote the manuscript. All authors discussed the results and commented on the manuscript.

\section{Additional information}

Supplementary Information accompanies this paper at http://www.nature.com/ naturecommunications

Competing financial interests: There are no competing financial interests.

Reprints and permission information is available online at http://npg.nature.com/ reprintsandpermissions/

How to cite this article: Wang, Y.-G. et al. Dynamic formation of single-atom catalytic active sites on ceria-supported gold nanoparticles. Nat. Commun. 6:6511 doi: 10.1038/ncomms7511 (2015).

\section{(c) (1)}

This work is licensed under a Creative Commons Attribution 4.0 International License. The images or other third party material in this article are included in the article's Creative Commons license, unless indicated otherwise in the credit line; if the material is not included under the Creative Commons license, users will need to obtain permission from the license holder to reproduce the material. To view a copy of this license, visit http://creativecommons.org/licenses/by/4.0/ 